\title{
Evaluation of a decision support app for nurses and case managers to facilitate aging in place of people with dementia. A randomized controlled laboratory experiment
}

Citation for published version (APA):

Thoma-Lurken, T., Bleijlevens, M. H. C., Lexis, M. A. S., \& Hamers, J. P. H. (2018). Evaluation of a decision support app for nurses and case managers to facilitate aging in place of people with dementia. A randomized controlled laboratory experiment. Geriatric Nursing, 39(6), 653-662.

https://doi.org/10.1016/j.gerinurse.2018.04.019

Document status and date:

Published: 01/01/2018

DOI:

10.1016/j.gerinurse.2018.04.019

Document Version:

Publisher's PDF, also known as Version of record

Document license:

Taverne

Please check the document version of this publication:

- A submitted manuscript is the version of the article upon submission and before peer-review. There can be important differences between the submitted version and the official published version of record. People interested in the research are advised to contact the author for the final version of the publication, or visit the DOI to the publisher's website.

- The final author version and the galley proof are versions of the publication after peer review.

- The final published version features the final layout of the paper including the volume, issue and page numbers.

Link to publication

\footnotetext{
General rights rights.

- You may freely distribute the URL identifying the publication in the public portal. please follow below link for the End User Agreement:

www.umlib.nl/taverne-license

Take down policy

If you believe that this document breaches copyright please contact us at:

repository@maastrichtuniversity.nl

providing details and we will investigate your claim.
}

Copyright and moral rights for the publications made accessible in the public portal are retained by the authors and/or other copyright owners and it is a condition of accessing publications that users recognise and abide by the legal requirements associated with these

- Users may download and print one copy of any publication from the public portal for the purpose of private study or research.

- You may not further distribute the material or use it for any profit-making activity or commercial gain

If the publication is distributed under the terms of Article 25fa of the Dutch Copyright Act, indicated by the "Taverne" license above, 
Feature Article

\title{
Evaluation of a decision support app for nurses and case managers to facilitate aging in place of people with dementia. A randomized controlled laboratory experiment
}

\author{
Theresa Thoma-Lürken, MSc ${ }^{\text {a,* }}$, Michel H.C. Bleijlevens, PhD ${ }^{a}$, Monique A.S. Lexis, PhD ${ }^{b}$, \\ Jan P.H. Hamers, PhD, RN ${ }^{\text {a }}$ \\ ${ }^{a}$ Maastricht University, CAPHRI Care and Public Health Research Institute, Department of Health Services Research, Living Lab on Ageing and Long-Term Care, \\ Maastricht, The Netherlands \\ ${ }^{\mathrm{b}}$ Zuyd University of Applied Sciences, Research Centre Technology in Care, Heerlen, The Netherlands
}

\section{A R T I C L E I N F O}

\section{Article history:}

Received 26 January 2018

Accepted 30 April 2018

Available online 29 May 2018

\section{Keywords:}

Aging-in-place

Case managers

Decision support

Dementia

Nurse

\begin{abstract}
A B S T R A C T
Detecting practical problems of persons with dementia (PwD) experience at home, and advising them on solutions to facilitate aging in place are complex and challenging tasks for nurses and case managers. In this two group randomized, controlled laboratory experiment, the efficacy of a decision support application aiming to increase nurses' and case managers' confidence in clinical judgment and decision-making was tested. The participants $(\mathrm{N}=67)$ assessed a case of a PwD within the problem domains: self-reliance, safety and informal care, and provided suggestions for possible solutions. Participants used either their regular procedure with (intervention group) or without the App (control group) to conduct these tasks. No statistically significant difference was found on the primary outcome measure, the overall level of confidence. However, nurses and case managers highly recommended use of the App in practice. To explain these results, more research on the potential added value of the App is needed.
\end{abstract}

(c) 2018 Elsevier Inc. All rights reserved.

\section{Introduction}

Worldwide, about 46.8 million people live with dementia and this number is expected to rapidly increase in the near future. ${ }^{1}$ People with dementia (PwD) often wish to live at home as long as possible ${ }^{2,3}$; however, they are especially susceptible to nursing home admission because of their increasing care and support needs. ${ }^{4,5}$ Facilitating aging in place and preventing nursing home admission of PwD is a common policy aim of many western countries nowadays, including the Netherlands. ${ }^{2,6,7}$ Hence, the complexity of community-based dementia care is increasing as PwD live longer in the community. A variety of solutions, such as different care and welfare services, and assistive technology are available with new interventions constantly evolving to support aging in place of PwD. ${ }^{8,9}$ However, finding the best suitable solution can be extremely challenging for PwD and their informal caregivers as they might not be aware of all possibilities. ${ }^{10,11}$ In addition, recent

\footnotetext{
Trialregister NR: NTR 6167.

* Corresponding author. Maastricht University, P.O. Box 616, 6200MD Maastricht, The Netherlands.

E-mail address: t.thoma@maastrichtuniversity.nl (T. Thoma-Lürken).
}

research has shown that informal caregivers of PwD have a substantial need for additional professional support and advice, e.g. on how to deal with behavioral problems or how to cope with emotional problems. ${ }^{11}$

In the Netherlands, professionals with a coordinating role in community-based dementia care support PwD to live at home as long as possible. ${ }^{12}$ This role is often fulfilled by district nurses and case managers (of whom the most have a nursing background). It is their task to detect important practical problems PwD and their informal caregiver's experience. In a previous study, it was found that practical problems within the domains of decreased self-reliance, safetyrelated problems and informal care and network related problems are the most threating ones with regard to the ability of PwD to live at home. ${ }^{13}$ Those problems may not always be easy to detect as PwD themselves, and sometimes also the informal caregiver, might not be aware of them. Examples are, informal caregivers who tried to keep up caregiving while they felt overburdened or PwD who lack awareness of their disease and therefore refuse support. Moreover, due to the progressive nature of the disease, the problems change over time and may become even more complex. In addition, nurses and case managers are expected to advise them on possible solutions to deal with these problems. These tasks require conscious clinical 
judgments about the expected consequences of the detected problems. Moreover, advice on possible solutions often results from complex decisions about the best suitable and available solution. To fulfill these diagnostic and advisory tasks, nurses and case managers need to have detailed insight into the living situation of the individual PwD, including their needs and enabling resources (e.g. informal support or financial resources) to fulfill these needs. ${ }^{14}$ Moreover, they need to be up to date with regard to possible solutions and should be able to make decisions about the added value of possible suitable solutions for the individual PwD.

Judgments and decisions made by nurses are characterized by uncertainty because the information available is sometimes unclear or incomplete, and the outcomes that result are often not directly predictable. ${ }^{15}$ Hence, nurses can lack confidence as to whether they have detected all problems and advised suitable solutions. Especially nurses who are new in a coordinating role might feel less confident, because knowledge and experience are known as important factors influencing decision-making. ${ }^{16}$ Research has shown that even when nurses have the same information they can make different judgments and decisions. ${ }^{15}$ For PwD and informal caregivers, this would mean that the detection of certain problems, and advice on possible solutions, highly depends on the specific nurse they encounter. This variability is not desirable, as ideally it should not matter whether they encounter a recently graduated nurse with less experience or a highly experienced nurse working in community-based dementia care for years. From a theoretical perspective, this variation could be explained by the use of different (combinations of) reasoning strategies for clinical judgment and decision- making. Two reasoning strategies nurses might use are: first, a fast, intuitive, relatively automatic form of reasoning which is based on expertise, and second, is the slower rational deliberative type of reasoning. When nurses use a more intuitionbased reasoning strategy instead of rational-analytic reasoning, without having the requisite expertise, it can cause variation in judgement and decisions. Moreover, in some situations nurses might not be aware of other decision options which remain beyond the scope their knowledge. ${ }^{15}$ As new solutions are constantly developed, it is very difficult for nurses to continuously be up to date with regards to the latest developments. A possibility to reduce this variation is to support nurses in the usage of more rational and deliberative reasoning strategies by means of education, guidelines or computerized decision support, ${ }^{15,17,18}$ and provide them easy access to recent information about possible solutions. Research has shown that computerized decision support systems may be valuable tools to support nurses to make judgements and decisions under uncertainty; however, not much high quality evidence is available yet supporting these tools. ${ }^{15,17}$

To the best of our knowledge, no decision support tool specifically for nurses and case managers in community-based dementia, guiding them through a problem assessment and providing them an overview of possible solutions, is currently available. Therefore, a decision support tool in the form of an application (App) on a tablet PC has been developed in a user-centered development process. ${ }^{19}$ The App consists of two parts: first a stepwise problem assessment focusing on the detection of problems within the three most important problem domains, i.e. decreased self-reliance, safety-related problems and informal care and network related problems. ${ }^{13}$ The problem assessment is partly based on validated questionnaires such as the Barthel index ${ }^{20}$ and the Self-perceived Pressure from Informal Care (SPPIC) $)^{21}$ and partly based on self-developed questions. The second part contains an overview of possible solutions to deal with the detected problems, such as care and support services, information sources and assistive technology. This overview is based on information retrieved from e.g. clinical guidelines, databases for assistive technology and expert interviews. In a previous study one low-fidelity (paper-based prototype) and three highfidelity prototypes have been tested with regards its usability by end-users, experts and researchers. We used a combination of different methods including heuristic evaluation, a think aloud method and a questionnaire to assess the overall satisfaction with the usage of the tool. ${ }^{22}$ This led to the conclusion that the decision support App is usable tool which in a next step needs to be tested with regard to its efficacy in a laboratory experiment.

Aim

The aim of this study was to evaluate the efficacy, potential added value and usability of a decision support App for nurses and case managers with a coordinating role in community-based dementia care, with the intention to improve problem assessment and provision of advice on possible solutions to deal with problems which may prevent PwD from living at home.

To evaluate the efficacy of the decision support App, the following questions were formulated:

1. Does use of the decision support App increase the nurses' and case managers' confidence in the correct outcome of their problem assessment and their ability to provide good advice on possible solutions? (primary outcome measure)

2. Does use of the decision support App increase uniformity between nurses and case managers with regard to the detection of problems preventing people with dementia from living at home?

3. Do the nurses and case managers who use the decision support App in addition to their usual procedure advise more possible solutions than nurses and case managers who only use their usual procedure?

To evaluate the potential added value and the usability of the decision support App, the following questions were formulated:

4. Do nurses and case managers regard the App as being of added value and what is, according to them, the added value of the App compared to their usual procedure?

5. To what extent is the decision support App a usable tool according to nurses and case managers and what are suggestions and recommendations for further improvement of usability?

\section{Martials and methods}

\section{Design}

A two group, randomized, controlled laboratory experiment was conducted to evaluate the efficacy of the decision support App for nurses and case managers with a coordinating role in communitybased dementia care. The allocation ratio was equal between both groups.

\section{Participants}

\section{Eligibility criteria}

Professionals with a (future) coordinating role in communitybased dementia care, including case managers, district nurses and nursing students being potential (prospective) users of the App, were eligible for participation. Dementia case managers and nurses were eligible if they were currently working in community-based care in the Netherlands. Nursing students were eligible when they were in their last two years of their bachelor studies. They were included as they might become a district nurse or case manager after graduation and, therefore, can represent the user group which is less experienced (the novices). 
Recruitment and setting of data collection

Nurses and case managers were recruited via the network organizations Living Lab in Aging and Long-Term Care South Limburg, ${ }^{23}$ the Centre of Expertise on Innovative Care and Technology, ${ }^{24}$ local network organization for dementia case management ${ }^{25}$ and three other long-term care organizations which were not affiliated with one of the network organizations. The students were recruited via the Zuyd University of Applied Sciences. Recruitment took place via various channels (e.g. via contact persons of longterm care organizations/network organizations, lectures and email invitations).

With all nurses/case managers/students who were willing to participate in the study, an individual meeting of a maximum of two hours was scheduled with a researcher (TTL, NS) or student assistant (FTH, AG), who conducted the data collection. The meetings took place in a meeting room either at the participants' workplace or at the university. The participants were asked to bring along all materials they usually use to conduct a problem assessment and to provide community-dwelling persons with dementia and their informal caregivers advices on possible solutions (e.g. own registration forms, questionnaires, tablet/laptop).

\section{Intervention group}

The intervention to be tested within this study was an App which was installed on an Apple iPad 2 (Fig. 1). The App guides the user through a problem assessment, focusing on three problem domains: decreased self-reliance, safety-related problems and informal care and social network related problems, which were found to be most challenging with regard to the ability to live at home. ${ }^{13}$ The problem assessment results in an overview of problems (problem statement) which is linked to an overview of possible solutions to deal with the detected problems. In the 'overview of possible solutions' part, the App directs the user to external websites and documents where more information on certain solutions can be found. The participants in the
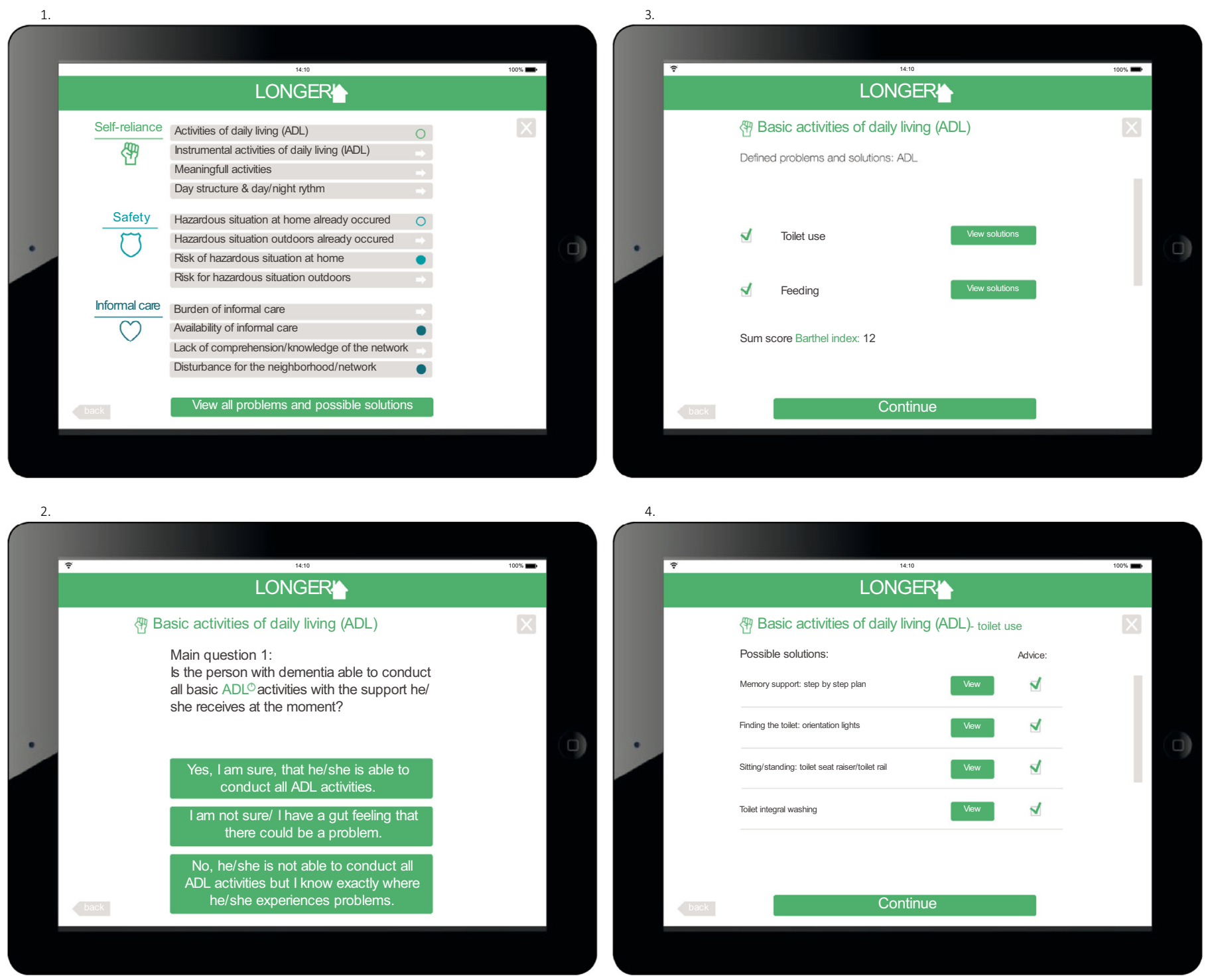

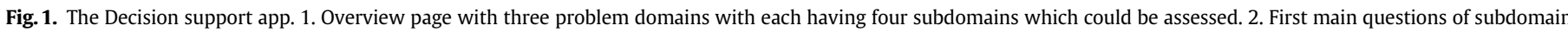

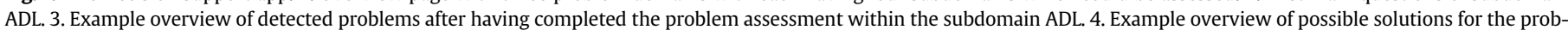
lem 'incontinence' 
intervention group were asked to conduct a problem assessment within three problem domains (self-reliance, safety and informal care/ social network) and to write down their advice on possible solutions to deal with the detected problems for one specific case of a community-dwelling PwD. The participants needed to use the App for conducting a problem assessment and or the provision of advice for possible solutions. They could use it in addition or in place of their regular procedure for these activities. Besides the App, the users received a short user manual which outlined the goal of the App, its content, its relationship with their regular procedure and general advice on how to select suitable solutions.

\section{Control group}

Participants in the control group were asked to conduct a problem assessment within three problem domains (self-reliance, safety and informal care/social network) and to write down their advice on possible solutions to deal with the detected problems for one specific case of a community-dwelling PwD according to their usual procedure.

\section{Randomization}

A random allocation sequence was generated by the principal researcher (TTL) using a random numbers generator to determine the group and the case for participants 1-40. From 40 onwards, block randomization was used with a block size of four to make sure that the groups were equally allocated, even if the expected number of participants was not reached. After participants were recruited, and had indicated that they were willing to participate in the study, the principal researcher assigned them randomly to either the intervention or the control group and subsequently to either case A or B.

\section{Procedure}

Fig. 2 provides an overview of the procedure followed during the study. All participants received a general introduction about the aim and the procedure of the study by one of the researchers (TTL, NS) or student assistants (FTH, AG) who conducted the data collection. The participants of the intervention group got a short verbal introduction to the App, time to read the user manual and the possibility to try working with the App

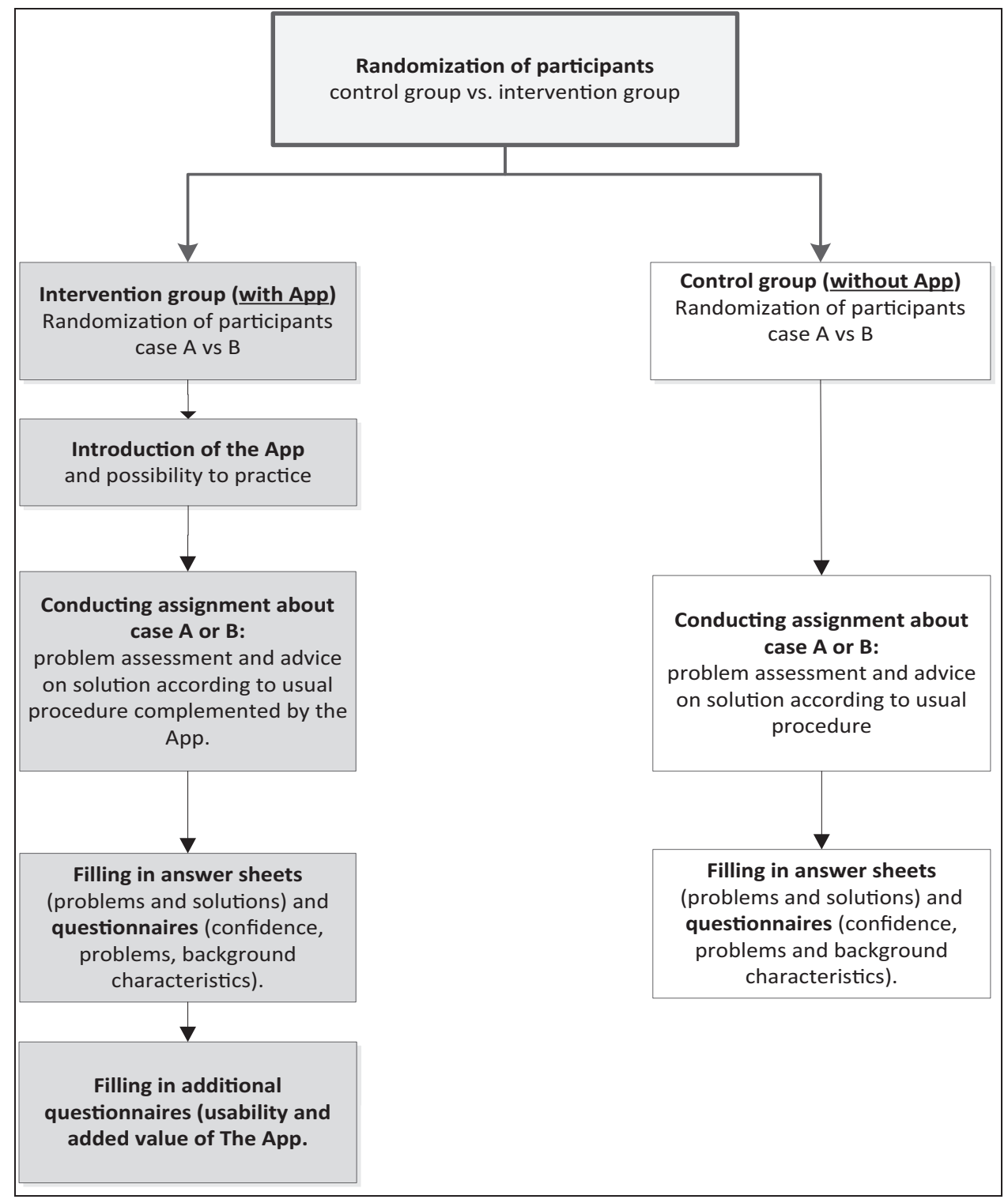

Fig. 2. Flowchart of procedure. 
for a maximum of $10 \mathrm{~min}$. Next, all participants got the assignment to analyze the case describing the situation of a community-dwelling PwD and his/her primary informal caregiver. Two different cases (A and B) were used to prevent case effects. The cases consisted of a written vignette (in the form of an email from a general practitioner) and a conversation with 'simulated' informal caregivers providing more information on the case based on a script (consisting of background information about the case and a set of standard answers). The cases were based on data retrieved from the RightTimePlaceCare study, a large European study investigating patterns of transition from home care towards institutional dementia care. ${ }^{26}$ The case descriptions were extended based on feedback from two experienced case managers and based on the experiences from a pilot study which was conducted with four participants (nurses and case managers) to test the proposed procedure. An example of a background description of a case can be found in Appendix 1.

During the study, participants in both groups were asked to conduct a problem assessment within three problem domains (self-reliance, safety and informal care/social network) and to write down their advice on possible solutions to deal with the detected problems on an answer sheet within one meeting. The participants in the control group were asked to conduct the problem assessment and give advice on possible solutions according to their usual procedure without the App. Participants in the intervention group were also asked to conduct the problem assessment and give advice on possible solutions according to their usual procedure; in addition, they needed to use the App.

All participants got $45 \mathrm{~min}$ to analyze the case (reading the vignette and talking to the simulated informal caregiver), to determine the problems and to write down their advice on possible solutions on the answer sheet. This time frame was chosen as it is known from practice that nurses and case managers often schedule about an hour for a first encounter. In this study however, we stated that nurses and case managers did not need to spent time introducing themselves and getting in touch with the informal caregiver; therefore, it was regarded as reasonable to set a time limit of 45 minutes.

The informal caregivers were simulated by a researcher (TTL, NS) from the project team or by a student assistant (FTH, AG) who had at least a bachelor's degree in health sciences or a related discipline. Simulation means that the researcher was equipped with a script (including the same background information about their case (A or B) and a set of standard answers to all questions which are incorporated in the App). With that background information at hand, they try to engage in an as natural possible conversation. They answered all questions the participants posed as far as they were within the scope their script; otherwise they rejected the question by stating that they do not have that information at the moment. Subsequently, the participants were asked to fill in questionnaires. Fig. 2 provides an overview of the procedure. Due to practical reasons, blinding of participants, simulated caregivers and outcome assessors was not possible.

\section{Outcomes}

\section{Primary outcome measure}

The primary outcome measure was the overall level of confidence with regard to problem assessment and the ability to provide advice on possible solutions, which was assessed by means of three items scored on a $10 \mathrm{~cm}$ horizontal VAS.

\section{Secondary outcome measures and background characteristics}

The secondary outcome measures include uniformity of decision -making, number of solutions provided, perceived added value and usability of the App. In addition, background characteristics of the participants were assessed (e.g. gender, age, educational level). Table 1 provides a detailed overview of the outcome measures that were assessed. All outcome measures and the background characteristics were assessed once after the participants had completed the assignment. Table 2

\section{Sample size calculation}

We calculated the sample size based on the primary outcome (level of confidence) measured on a $10 \mathrm{~cm}$ visual analogue scale (VAS). Assuming an alpha of 0.05 (two-tailed testing), and beta of 0.10 and an expected mean difference of two $\mathrm{cm}$, the required sample size was $n=33$ per group $(n=66$ in total).

Table 1

Overview of outcome measures and analysis.

\begin{tabular}{|c|c|c|}
\hline Concept & Operationalization & Control/ intervention group \\
\hline $\begin{array}{l}\text { Level of confidence } \\
\text { (primary outcome } \\
\text { measure) }\end{array}$ & $\begin{array}{l}\text { Combined measure: mean of three items measured on visual analog scales, a } 10 \mathrm{~cm} \text { horizontal line } \\
\quad(0=\text { not confident at all; } 10=\text { very confident }) \\
\text { 1. 'How sure are you that you have conducted a good problem assessment?' } \\
\text { 2. 'How sure are you that you have a good overview of possible solutions for the detected problems?' } \\
\text { 3. 'How sure are you that you provided good advice on possible solutions for the detected problems?' }\end{array}$ & Both \\
\hline $\begin{array}{l}\text { Uniformity in } \\
\text { problem assessment }\end{array}$ & $\begin{array}{l}\text { Three items measured on a visual analog scales, a } 10 \mathrm{~cm} \text { horizontal line }(0=\text { low extent of problems; } \\
10=\text { high extent of problems) } \\
\text { 1. 'To what extent do you think this case contains problems with regard to decreased self-reliance?' } \\
\text { 2. 'To what extent do you think this case contains problems with regard to safety?' } \\
\text { 3. 'To what extent do you think this case contains problems with regard to informal care/social } \\
\text { network?' }\end{array}$ & Both \\
\hline & Answer sheet describing the detected problems. & Both \\
\hline $\begin{array}{l}\text { Advice on possible } \\
\text { solutions }\end{array}$ & Answer sheet describing the advice for possible solutions for the detected problems & Both \\
\hline Perceived added value & $\begin{array}{l}\text { Three open-ended questions } \\
\text { 1. 'Would you like to use this application in practice? If yes, why? If no, why not?' } \\
\text { 2. 'What is, according to you, the added value of this application for daily practice?' } \\
\text { 3. 'Would you like to recommend this application to your colleagues? If yes, why? If no, why not?' }\end{array}$ & Intervention group only \\
\hline Usability & $\begin{array}{l}\text { Dutch version of the post study system usability questionnaire (19 items) }{ }^{27,28} \text { and calculating the } \\
\text { scale scores for; } \\
\text { - Overall satisfaction (item } 1-19) \\
\text { - System usefulness (item } 1-8 \text { ) } \\
\text { - Information quality (item } 9-15 \text { ) } \\
\text { - Interface quality (item, } 16-18 \text { ) } \\
\text { One additional open-ended question: 'Do you have any further suggestions for improvement of the } \\
\text { App?' }\end{array}$ & Intervention group only \\
\hline $\begin{array}{l}\text { Background } \\
\text { characteristics }\end{array}$ & $\begin{array}{l}\text { Age, gender, educational level } \\
\text { For nurses/case managers only: primary function (case manager/district nurse) }\end{array}$ & Both \\
\hline
\end{tabular}


Table 2

Background characteristics of the participants.

\begin{tabular}{|c|c|c|c|c|}
\hline \multirow{2}{*}{$\begin{array}{l}\text { Characteristics } \\
\text { Case }(\mathbf{A} \text { or } \mathbf{B})\end{array}$} & \multicolumn{2}{|c|}{ Intervention $(\mathrm{n}=34)$} & \multicolumn{2}{|c|}{ Control $(n=33)$} \\
\hline & $A(n=17)$ & $B(n=17)$ & $A(n=17)$ & $B(n=16)$ \\
\hline Mean age in years (SD) & $41.4(13.1)$ & & $40.9(13.1)$ & \\
\hline \multicolumn{5}{|l|}{ Sex } \\
\hline Male & $\mathrm{n}=2(6 \%)$ & & $\mathrm{n}=5(15 \%)$ & \\
\hline Female & $\mathrm{n}=32(94 \%)$ & & $\mathrm{n}=28(85 \%)$ & \\
\hline \multicolumn{5}{|l|}{ Function } \\
\hline District nurse & $\mathrm{n}=14(41 \%)$ & & $\mathrm{n}=13(40 \%)$ & \\
\hline Case manager & $\mathrm{n}=13(38 \%)$ & & $\mathrm{n}=16(48 \%)$ & \\
\hline Nursing student & $\mathrm{n}=7(21 \%)$ & & $\mathrm{n}=4(12 \%)$ & \\
\hline \multicolumn{5}{|l|}{ Educational level } \\
\hline Academic education & $\mathrm{n}=1(3 \%)$ & & $\mathrm{n}=0(0 \%)$ & \\
\hline Bachelor educated & $\mathrm{n}=21(62 \%)$ & & $\mathrm{n}=23(70 \%)$ & \\
\hline Vocationally trained & $\mathrm{n}=4(12 \%)$ & & $\mathrm{n}=5(12 \%)$ & \\
\hline Bachelor students & $\mathrm{n}=8(24 \%)$ & & $\mathrm{n}=5(12 \%)$ & \\
\hline
\end{tabular}

SD: Standard deviation.

Data-analysis

Quantitative data-analysis

All statistical analyses were conducted using IBM SPSS 23.0.

Analysis of primary outcome measure. To analyze the overall level of confidence, we first calculated the mean score of all three items measured on a VAS. Then the means from both groups were compared to means of an independent sample t-test.

Analysis of secondary outcome measures and background characteristic$s$. The secondary outcome uniformity was measured in two different ways. First by means of three items on a VAS scale, which were analyzed using Levene's test of equality of variances. Second, by means of comparing the problems detected (as written on the answers sheets) between both groups. To do so, the problems described by the participants on the answer sheet were clustered around the three problem domains (self-reliance, safety and informal care/social network and others) by the project team. In a next step, sub-clusters describing specific problems were formed based on the data. Finally, it was counted how many participants detected the specific problems. The number of problems detected per group was analyzed by means of Pearson's Chi square tests. The average number of solutions provided per problem for the secondary outcome measure was analyzed by means of an independent sample t-test to compare the difference between means. Descriptive techniques were used to analyze background characteristics.

The scores on the PSSUQ were analyzed through descriptive analyses (means and standard deviations) and subsequently calculating scale scores (means and standard deviations) for: Overall satisfaction (item 1-19), System usefulness (item 1-8), Information quality (item 9-15), and Interface quality (item, 16-18). Background characteristics were analyzed through descriptive analyses (frequencies, means and standard deviations).

\section{Qualitative data-analysis}

The secondary outcome measure, perceived added value of the App, was analyzed according to the principles of conventional content analysis. ${ }^{29}$ To ensure the trustworthiness of the qualitative data several measures have been taken: To ensure credibility data triangulation was used. The participants were explicitly asked to describe their perceptions about the added value of the App. In addition they were also asked if they would like to use the App in practice and if they would recommend its usage to a colleague and why. The information provided on all three questions was used to get insight into the perceived added value. Moreover, the quantitative data about the willingness to use the App can be regarded as verification of the perceived added value. To ensure the confirmability of the findings, which means reducing potential personal bias by the researcher, the analysis was conducted by two researchers (blinded for review) independently. They individually coded the statements of the participants. In case of discrepancies in coding, the researchers discussed the theme to reach consensus.

\section{Ethics}

The study protocol was reviewed by the medical ethics committee of Zuyderland-Zuyd (16-N-222), they indicated that this research did not fall under the scope of the Medical Research Involving Human Subjects Act (WMO) and that it does not need to undergo further review. Participation was strictly voluntary and all participants gave their written informed consent to participate in the study.

\section{Results}

The study was conducted in the period between January and May 2017.

\section{Participants}

In total 71 persons gave verbal consent to participate. One of them was not eligible because he/she was neither a district nurse or case manager nor a student. Three participants retracted their verbal consent. All three mentioned personal time constraints as reason to refuse participation. Finally, 67 participants entered the study and gave written informed consent. There was no drop out during the study, all participants who started the meeting, finished it. The mean age was 41 years and the majority of participants were female $(n=60)$. In total, 29 case managers, 27 district nurses and 11 students participated. The majority of participants were educated at the bachelor's level.

\section{Primary outcome: level of confidence}

There was no statistically significant difference in the overall level of confidence (with regard to problem assessment, overview of solutions and advice on possible solutions) between both groups (Table 3). Also, with regard to the individual items (problem assessment, overview of solutions and advice on possible solutions), no statistically significant differences between both groups were found.

\section{Secondary outcomes}

\section{Uniformity}

Overall, there was no statistically significant difference in uniformity of problem assessment between both groups. When comparing the variances of scores on the three items measuring the extent of a problem in the three problem domains self-reliance, safety and informal care/ social network, both groups did not significantly differ (Table 4).

When comparing the number of participants who detected at least one problem within the three domains, also no statistically significant difference was found. In the intervention group, $88 \%$ of the participants detected a problem with regard to decreased selfreliance vs $94 \%$ in the control group (p-value 0.414 ); the same is true for safety-related problems $74 \%$ in the intervention group vs. $85 \%$ in the control group ( $\mathrm{p}$-value 0.225 ), and informal care and network-related problems $94 \%$ intervention group vs $85 \%$ control group ( $p$-value 0.215 ). When looking at the problems which were detected by the participants more in detail, a variety of different 
Table 3

Comparison of the mean level of confidence between both groups.

\begin{tabular}{|c|c|c|c|}
\hline & Intervention $(\mathrm{n}=34)$ & Control $(n=33)$ & Comparison of differences in mean $^{\mathrm{a}}: \mathrm{p}$-value $\mathrm{b}^{\mathrm{b}}$ \\
\hline $\begin{array}{l}\text { Overall level of confidence } \\
\text { Mean (SD) }\end{array}$ & $6.93(0.97)$ & $6.66(1.25)$ & 0.324 \\
\hline \multicolumn{4}{|l|}{ Individual items: } \\
\hline $\begin{array}{l}\text { Level of confidence: problem assessment } \\
\text { Mean (SD) }\end{array}$ & $6.63(1.22)$ & $6.33(1.39)$ & 0.354 \\
\hline $\begin{array}{l}\text { Level of confidence: overview of possible solutions } \\
\text { Mean (SD) }\end{array}$ & $6.88(1.16)$ & $6.68(1.34)$ & 0.531 \\
\hline $\begin{array}{l}\text { Level of confidence: advices on possible solutions } \\
\text { Mean (SD) }\end{array}$ & $7.29(0.97)$ & $6.96(1.34)$ & 0.260 \\
\hline
\end{tabular}

a Independent sample t-test.

b alpha 0.05 .

Table 4

Comparison of the variance in judgment of the extent of a problem between both groups.

\begin{tabular}{|c|c|c|c|}
\hline & Intervention $(\mathrm{n}=34)$ & Control $(n=33)$ & $\begin{array}{l}\text { Comparison of the variances in scores }{ }^{\mathrm{a}} \text { on VAS } \\
\text { indicating the extent of a problem: } \mathrm{p} \text {-value }{ }^{\mathrm{b}}\end{array}$ \\
\hline Problem self-reliance: Mean (SD) & $7.35(2.28)$ & $7.62(1.43)$ & 0.091 \\
\hline Problem safety: Mean (SD) & $6.29(2.16)$ & $6.46(1.89)$ & 0.324 \\
\hline Problem informal care/network: Mean (SD) & $7.68(2.21)$ & $8.06(1.68)$ & 0.156 \\
\hline
\end{tabular}

a Levene's test of homogeneity of variances.

b alpha 0.05 .

problems with in the three domains were detected. Frequently detected problems in both groups included lack of meaningful activities, problems with ADL activities, safety problems with regard to nutritional status and high burden of informal caregiver. Participants also described a variety of problems which could not be summarized under one of the three domains, such as mood or behavioral problems. It was not the case that the intervention group detected more of the same problems compared to the participants in the control group, as we had expected beforehand.

\section{Advice on possible solutions}

There was no statistically significant difference in the mean number of solutions provided by the participants in the intervention and control groups for the three most detected problems within each problem in each problem domain (decreased self-reliance, safety and informal care), as Table 5 shows.

\section{Added value}

Among the 34 participants in the intervention group, 30 indicated that they would like to use the App during their daily work. Four participants said they were neutral, they provided arguments for and against use of the App in practice. No participant indicated that he/she was not willing to use the tool in practice. From all users, 33 stated that they would recommend the App to a colleague and one participant indicated they were undecided about

Table 5

Comparison of the average number of solutions provided per problem.

\begin{tabular}{|c|c|c|c|}
\hline $\begin{array}{l}\text { Average number of solutions } \\
\text { provided for the detected } \\
\text { problems }\end{array}$ & $\begin{array}{l}\text { Intervention } \\
(n=34) \\
\text { mean }(S D)\end{array}$ & $\begin{array}{l}\text { Control } \\
(\mathrm{n}=33) \\
\text { mean }(\mathrm{SD})\end{array}$ & $\begin{array}{l}\text { Comparison of } \\
\text { differences in } \\
\text { mean }^{\mathrm{a}}: \mathrm{p} \text {-value }\end{array}$ \\
\hline (Meaningful) daily activities & $2.2(1.1)$ & $1.8(0.8)$ & 0.253 \\
\hline Safety (eating) & $2.3(1.4)$ & $2.0(1.1)$ & 0.561 \\
\hline High burden of informal care & $2.8(1.4)$ & $2.9(1.4)$ & 0.833 \\
\hline
\end{tabular}

SD: Standard deviation.

a Independent sample t-test.

b alpha 0.05 . recommending the App. When asking the participants what, according to them, is the potential added value of the App and to provide arguments for the usage of the tool in practice, they came up with two major themes: first, they described that the App can help them to obtain better insight in the situation of the PwD and the App can be viewed as a control measure to check whether one has detected the major problems. Second, they indicated that they value the overview of solutions as it contained besides familiar solutions, also new/unknown ones. In addition, they indicated that that they regard it as an user-friendly tool which might help them to work more efficiently. Moreover, they also stated that they see the App as complementary to their usual procedure.

\section{Usability}

With regard to usability of the App, the results of the PSSUQ indicate that the participants were overall satisfied with the usability of the App, as the mean score of 1.91 of the PSSUQ indicates (Table 6).

\section{Discussion}

This study has provided no evidence that the decision support App improved nurses' and case managers' confidence in problem assessment or the provision of advice for possible solutions. With regard to the secondary outcome measures, no statistically significant differences were found in uniformity of the problems detected or the number of solutions provided for the detected problems between the

Table 6

Usability of the decision support App.

\begin{tabular}{ll}
\hline Scores on PSSUQ & Mean scores (SD); Range $1-7^{\mathrm{a}}$ \\
\hline Overall satisfaction & $1.91(0.61)$ \\
System Usefulness & $1.96(0.62)$ \\
Information quality & $1.83(0.76)$ \\
Interface quality & $1.94(0.67)$ \\
\hline
\end{tabular}

SD: Standard deviation.

a Lower scores indicate better usability. 
intervention and control group. However, among participants there was a high willingness to use the App in practice and they valued the App as user-friendly. Participants indicated that the App could help them get better insight into the problems experienced by the person with dementia and their informal caregivers and to find new or unknown solutions for the detected problems.

\section{Explanation of the results and implications}

The study has shown contradictory results, as no effects on confidence, uniformity or quantity of solutions were found, but participants were very willing to use the App and appreciated its added value. One possible explanation is that the App is indeed not of added value and that the willingness to use the App is based on socially desirable answers. However, there are other arguments which might explain the lack of efficacy in contrast to the high willingness to use the App in practice. During the study, the participants in the intervention group had limited time to explore the features of the App and to get accustomed to it. Often participants had insufficient time to use all problem assessment elements, to run through all possible solutions provided and to view additional information. Therefore, participants in the intervention group may have felt more time pressure compared to those in the control group. From research, it is known that time pressure has a negative influence on decision accuracy and the choices for interventions, even in experienced nurses. ${ }^{30}$ The aspect of time pressure might have also caused the participants in the intervention group to rely mainly on solutions they already knew and with which they had good experiences.

Moreover, participants were expected to immediately use a new technology and to combine it with their usual procedure. Even though the App was regarded as very user-friendly, it remains challenging to immediately integrate a new technology in an existing routine. Another factor which might have influenced the results in favor of the control group is the assignment to assess the problems within three domains, this might have caused participants in the control group, who wouldn't pay specific attention to those problems, to investigate all three in detail. Moreover, the chosen procedure in the laboratory experiment, which according to several participants felt like an exam, could have triggered the participants to assess the situation as explicitly as possible and to automatically use a more rational and deliberative reasoning strategy. Using real life cases was impossible; as it would have been unethical ask different nurses/case managers and students to assess the same case. Practically, this would have meant that an informal caregiver had to undergo about 30 conversations with different participants about exactly the same topic. Using different cases would have meant that a comparison of the assessments and advice of different participants for the same cases would not be possible. However, it remains unclear to what extent these simulations represent reality. Even though the cases were based on information from real life cases and the simulated informal caregivers tried to engage in a natural conversation, another drawback of using cases and simulations is that the participants were not able to see the PwD and his/her real living environment. As a result, parts of the regular procedure could not be applied, e.g. checking for unsafe furniture or observing the behavior or emotions of the PwD. However, pre-implementation evaluations, using simulations, to test the efficacy of decision support tools for professionals is recommended as this can save costs by preventing the implementation of poorly evaluated tools in practice. In addition, it is possibility to discover problems to be refined before actual implementation of the tool in practice. ${ }^{31}$

It remains unclear why the participants were so eager to use the App in daily practice. More research is needed to unfold their underlying perceptions regarding the potential added value of the App. Depending on the results, it needs to be defined how the added value can be operationalized to study the effectiveness of the App in practice. In addition, more research is needed to study the long-term effects of the applications within the App when participants had more time to get used to it and to integrate the App in their daily working routine. This could be done in a field study comparing two groups, an intervention group (with App) and control group (without App) of similar professional caregivers with similar client populations over a longer period of time with regard to their confidence in problem assessment and providing advices on possible solutions. In such a study it might be worthwhile to also investigate whether the App increases nurses' and case managers' efficiency in finding suitable solutions, as they described this as a potential added value. A field study would also allow for measuring the effect of the App at the level of the PwD in addition to the outcomes on a nurse level.

\section{Strengths and limitations of the study}

Strengths of this study were: first, the rigorous study design in the form of an RCT, which allows conclusions to be drawn on causal relationships. Second, contamination, which is often a problem in real life studies testing decision support systems, ${ }^{17}$ was prevented by conducting the assessment and all related measurements in just one meeting. At the end of each meeting all participants were requested to handle all information confidentially and not to share any information about the cases, the procedure or the App with their colleagues until the end of the study.

This study is not without limitations. First, due to feasibility reasons blinding was not possible. The principal researcher (blinded for review) was responsible for the recruitment of participants, the randomization, the planning of the meetings and also involved in data collection as one of the 'simulated' informal caregivers. Also, the other researchers who acted as simulated caregivers were not blinded as they also needed to introduce the App and hand out the additional questionnaire to the participant of the intervention group.

Second, the chosen recruitment method, via various channels (e.g. via contact persons of organizations or lectures) and the dependence on volunteers to participate in a two hours sessions might have led to selection bias. The sample might include more motivated and research-minded nurses, case managers and students than average in that population.

Third, to measure the level of uniformity, inter-judge comparisons were used as method, as there was no gold standard to compare the results. The disadvantage of this method is the risk of systematic measurement errors. Expert-panel consensus could have been used as an alternative method. ${ }^{32}$ Fourth, although participants were randomly allocated to either intervention or control group, there is a chance that the groups were different with regard to their confidence levels at baseline due to the relatively small sample size. As the primary outcome measure could not be assessed beforehand without having conducted the assignment, a baseline measurement of the primary outcome was not possible. Consequentially, we are not able to check and eventually correct for baseline differences. Fifth, in the evaluation of computerized decisions support systems, it is desirable to also test a paper-based counterpart to evaluate the added value of the technology. ${ }^{17}$ However, due to the large quantity of information which is included in the App testing a paper based version was not feasible.

\section{Conclusion}

This randomized, controlled laboratory experiment did not show promising results with regard to efficacy of the App in terms of increased nurse confidence, increased uniformity in problem 
assessment and increased quantity of solutions advised per problem. However, the study did show a high willingness of nurses and case managers to use the App in practice and to recommend usage of the App to colleagues. More research is needed to explain these contradictory results and to explore the potential added value of using the App more in detail.

\section{Acknowledgments}

We wish to thank all district nurses, case managers and students who participated in this study. In addition we want to thank Nadine Spierts, Anke Gulikers and Fabiënne ter Huurne for their contribution to the data collection.

\section{Appendix. Example background information about case A- Mrs. $\mathrm{H}$}

Background information for the researcher who acts as the simulated informal caregiver

Formal care and support at home: Mrs. H receives home care twice a day. She receives supports with washing, getting dressed and changing her incontinence materials. Additionally, Mrs. H receives support from a domestic worker once a week. Besides the general practitioner, the home care professionals and the domestic worker no other professional caregivers are involved in the case.

Home environment: Mrs. $\mathrm{H}$. is a widow, who has been living alone since her husband died two years ago. For the past ten years she has been living in an apartment on the $3^{\text {rd }}$ floor. The apartment has a standard layout (bathroom with a shower, 2 bedrooms, separate toilet and an open kitchen in the living area).The toilet has a normal height and no rails to support safely sitting down and getting back up. Mrs. $\mathrm{H}$ is quite tall and the toilet is too low for her. She has no personal safety alarm system at home. Mrs. H uses an elevator to enter her apartment and to go to the ground floor. Her daughter doubts whether Mrs. $\mathrm{H}$. is still able to use the elevator on her own.

Interests: Mrs. $\mathrm{H}$ has always loved cooking and gardening. Ever since moving to the apartment with her husband ten years ago, Mrs. $\mathrm{H}$. has not had a garden anymore. Mrs. $\mathrm{H}$. is a religious person (Roman (atholic). She used to go to church every Sunday, but since a few years she has been going less frequently. Mrs. $\mathrm{H}$ never liked being involved in any form of groups or associations.

Activities of daily living (ADL): Mrs. $\mathrm{H}$ needs major help with everyday activities including washing, getting dressed and eating. She can walk short distances with her walker. She is incontinent and wears pads.

Physical health: Mrs. H's physical health is generally quite good, although back pain limits her mobility. The back pain is caused by degenerative disc disease. She does not wear glasses nor a hearing aid. She has a high blood pressure which is being kept under control with medication. In the past she once had a gastrointestinal bleeding.

Mental health: Mrs. H was diagnosed with Alzheimer's disease five years ago and her mental state has declined very fast since her husband's death. She frequently does not recognize her daughter or other family members, is disorientated to time and place and has marked short-term memory problems. Whilst she is usually quiet and pleasant in mood, she sometimes experiences delusions (false, fixed beliefs not amenable to reason), screams and resists care. Generally it is easy to cope with these problems by gently touching/hugging her and changing the topic of conversation.
Informal care: Mrs. $\mathrm{H}$ has one daughter. The daughter is married and has two teenage sons. She and her husband also work full time. It is thus not possible for them to meet all Mrs. X's needs. She copes with her mother's diagnosis of dementia very well.

Attitude towards future care: Mrs. X's daughter would find it difficult to leave her mother in a nursing home, but recognizes that the family cannot provide the 24/7 care she needs. Whilst it is not possible to discern Mrs. X's own preference now, in the past she did not want to go into a nursing home.

\section{References}

1. Prince M, Wimo A, Guerchet M, Ali GC, Wu YT, Prina M. World Alzheimer Report 2015. The global impact of dementia. An analysis of prevalence, incidence, cost and trends; 2015. Published August; 2015. https://www.alz.co.uk/research/worldreport-2015. Accessed September 2017.

2. World Health Organization. Alzheimer's Disease International. Dementia: A public health priority; 2012. Published; 2012. http://apps.who.int/iris/bitstream/10665 75263/1/9789241564458_eng.pdf?ua=1. Accessed October 2014

3. von Kutzleben M, Schmid W, Halek M, Holle B, Bartholomeyczik S. Communitydwelling persons with dementia: What do they need? What do they demand? What do they do? A systematic review on the subjective experiences of persons with dementia. Aging Ment Health. 2012;16:378-390.

4. Prince M, Prina M, Guerchet M. World Alzheimer Report 2013. Journey of caring. An analysis of long-term care for dementia; 2013. Published September; 2013. https:/ www.alz.co.uk/research/WorldAlzheimerReport2013.pdf. Accessed October 2014.

5. Eaker ED, Vierkant RA, Mickel SF. Predictors of nursing home admission and/or death in incident Alzheimer's disease and other dementia cases compared to controls: A population-based study. J Clin Epidemiol. 2002;55:462-468.

6. Moïse P, Schwarzinger M, Um M. Dementia care in 9 OECD countries; 2004. Published; 2004. http://dx.doi.org/10.1787/485700737071. Accessed October 2014.

7. Maarse JAM, Jeurissen PP. The policy and politics of the 2015 long-term care reform in the Netherlands. Health Policy (New York). 2016;120:241-245.

8. Thoma-Lürken T, Bleijlevens MH, Lexis MA, Hamers JP, de Witte LP. An overview of potential labor-saving and quality-improving innovations in long-term care for older people. J Am Med Dir Assoc. 2015;16:482-489.

9. Gibson G, Newton L, Pritchard G, Finch T, Brittain K, Robinson L. The provision of assistive technology products and services for people with dementia in the United Kingdom. Dementia. 2014;5:681-701.

10. van der Roest HG, Meiland FJ, Comijs HC, et al. What do community-dwelling people with dementia need? A survey of those who are known to care and welfare services. Int Psychogeriatr. 2009;21:949-965.

11. Peeters JM, Van Beek AP, Meerveld JH, Spreeuwenberg PM, Francke AL. Informal caregivers of persons with dementia, their use of and needs for specific professional support: a survey of the National Dementia Programme. BMC Nurs. 2010;9:9.

12. Alzheimer Nederland, Vilans. Zorgstandaard Dementie; 2013. Published 18 July; 2013. http://www.vilans.nl/docs/vilans/publicaties/Zorgstandaard_Dementie.pdf. Accessed October 2014.

13. Thoma-Lürken T, Bleijlevens MHC, Lexis MAS, de Witte LP, Hamers JPH. Facilitating aging in place: a qualitative study of practical problems preventing people with dementia from living at home. Geriatr Nurs. 2018;39:29-38.

14. van Bilsen PM, Hamers JP, Groot W, Spreeuwenberg C. Demand of elderly people for residential care: An exploratory study. BMC Health Serv Res. 2006;6:39.

15. Thompson C, Aitken L, Doran D, Dowding D. An agenda for clinical decision making and judgement in nursing research and education. Int J Nurs Stud. 2013;50:1720-1726.

16. Hamers JP, Huijer Abu-Saad H, Halfens RJ. Diagnostic process and decision making in nursing: A literature review. J Prof Nurs. 1994;10:154-163.

17. Randell R, Mitchell N, Dowding D, Cullum N, Thompson C. Effects of computerized decision support systems on nursing performance and patient outcomes: a systematic review. J Health Serv Res Policy. 2007;12:242-251.

18. Thompson C, Stapley S. Do educational interventions improve nurses' clinical decision making and judgement? A systematic review. Int J Nurs Stud. 2011;48:881-893.

19. Thoma-Lürken T, Lexis MAS, Bleijlevens MHC, Hamers JPH. Development and usability of a decision support App for nurses to facilitate aging in place of people with dementia. Appl Nurs Res. 2018;42:35-44.

20. de Haan R, Limburg M, Schuling J, Broeshart J, Jonkers L, van Zuylen P. Klinimetrische evaluatie van de Barthel Index, een mat voor beperkingen in het dagelijks functioneren. Ned Tijdschr Geneeskd. 1993;137:917-921.

21. Pot AM, Deeg DJ, van Dyck R, Jonker C. Psychological distress of caregivers: the mediator effect of caregiving appraisal. Patient Educ Couns. 1998;34:43-51.

22. Thoma-Lürken T, Bleijlevens MH, Lexis MA, Hamers J. A decision support app for registered nurses to facilitate aging in place of people with dementia. Innovation Aging. 2017;1(suppl 1):1-1452.

23. Verbeek H, Zwakhalen SM, Schols JM, Hamers JP. Keys to successfully embedding scientific research in nursing homes: a win-win perspective. J Am Med Dir Assoc. 2013;14:855-857.

24. Centre of Expertise for Innovative Care and Technology. Over EIZT/ZTL; http://www. innovatiesindezorg.eu/over/over-eizt-ztl/. Accessed 17 July 2015. 
25. Hulp bij Dementie. Hulp bij Dementie; http://www.hulpbijdementie.nl/. Accessed January 2016.

26. Verbeek H, Meyer G, Leino-Kilpi H, et al. A European study investigating patterns of transition from home care towards institutional dementia care: The protocol of a RightTimePlaceCare study. BMC Public Health. 2012;12:1-10.

27. van der Weegen S, Verwey R, Tange HJ, Spreeuwenberg MD, de Witte LP. Usability testing of a monitoring and feedback tool to stimulate physical activity. Patient Pref Adherence. 2014;8:311-322.

28. Lewis JR. IBM computer usability satisfaction questionnaires: psychometric evaluation and instructions for use. Int J Hum Comp Interact. 1995;7:57-78.
29. Hsieh H-F, Shannon SE. Three approaches to qualitative content analysis. Qual Health Res. 2005;15:1277-1288.

30. Thompson C, Dalgleish L, Bucknall T, et al. The effects of time pressure and experience on nurses' risk assessment decisions: a signal detection analysis. Nurs Res, 2008;57:302-311.

31. Sousa VE, Lopez KD, Febretti A, et al. Use of simulation to study nurses' acceptance and nonacceptance of clinical decision support suggestions. Comput Inform Nurs. 2015;33:465-472.

32. Dowding D, Thompson C. Measuring the quality of judgement and decision-making in nursing. J Adv Nurs. 2003;44:49-57. 